\title{
Effect of discharge conference on rehospitalization among older patients: An analysis of administrative claims data in Japan
}

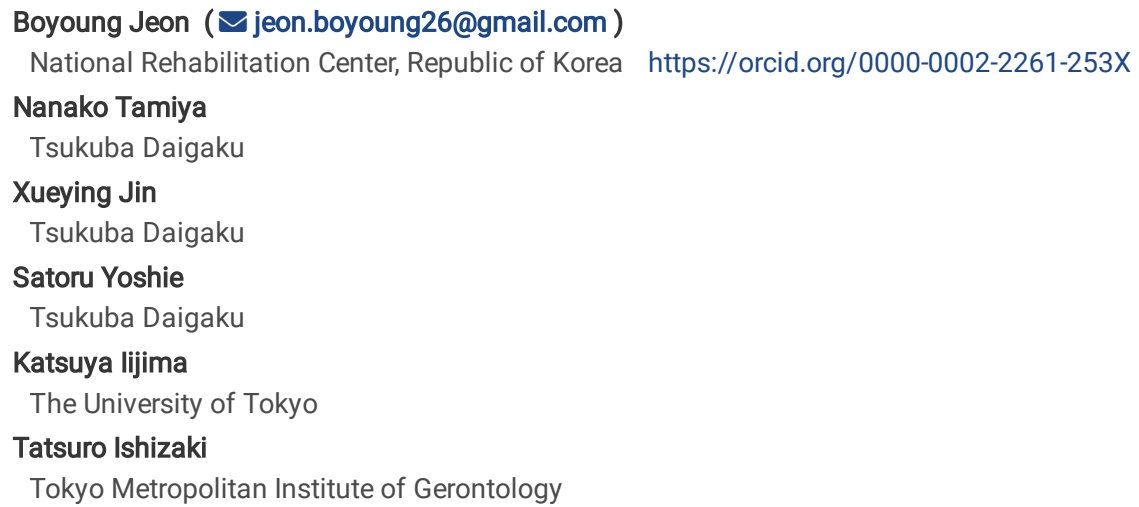

Research article

Keywords: Discharge Conference, Hospital Readmission, Continuum of Care, Health Policies, Discharge Planning

Posted Date: June 8th, 2020

DOI: https://doi.org/10.21203/rs.3.rs-32155/v1

License: (c) (1) This work is licensed under a Creative Commons Attribution 4.0 International License. Read Full License 


\section{Abstract \\ Background}

The policy of discharge conference has function of guiding patients to stay at community. This study aims to investigate the effect of a discharge conference on a probability of hospital readmission and readmission costs among older patients in Japan.

\section{Methods}

We included 8,096 individuals admitted to acute care hospitals, using health and long-term care insurance claims data on older patients (age $\geq 75$ years) in a suburban city in Japan, from April 2012 to September 2013. To balance the two groups according to whether a patient received a service of discharge conference or not, we used propensity score matching method. We identified readmission within 360 days from discharges and estimated the impact of a discharge conference on the probability of readmission and readmission costs using multiple logistic and linear regression model.

\section{Results}

Among patients who discharged from an acute care hospital, 367 (4.5\%) received a discharge conference. Using the matching method, 304 participants in a control group was matched to 304 participants in a discharge conference group. Readmission rate was $21.1 \%$ in patients with a discharge conference and $23.0 \%$ in those without a discharge conference. Although there was no significant effect of discharge conference on probability of readmission, but it showed significant effect on lower cost per day.

\section{Conclusions}

These results imply a discharge conference has effect on mitigating cost per day of readmission after adjusting for confounding. This study suggests that there are potential possibilities in the policy of discharge conference on reducing the readmission costs per day amongst older patients.

\section{Background}

With an increasing emphasis on comprehensive and seamless care, discharge services have been paid attention. When older adults are discharged from acute care, they have to interface with multiple providers and payment systems[1]. The discharge services, like discharge planning, discharge summary, or discharge conference, have been considered as means to prevent readmission, improve the continuum of care, and reduce the healthcare costs [2-7].

In Japan, universal health insurance system and long-term care insurance system cover all the population of older people with a relatively wide range of service coverage [8]. However, when a person discharge from hospital, coordination between acute care, sub-acute care, and home and community-based care is not easy [9]. As continuity of care became more important, a new benefit coverage has been added to the fee schedule of "cooperative discharge instructions at hospital" since 2008 [10]. It began to incentivize a "discharge conference" that includes the participation of more than 3 professionals, like community physicians or nurses, dentists, pharmacists, home visiting nurses, etc. [10]. In addition, coordination between acute care physicians and community long-term care providers started to be covered by health insurance fee schedule, as of 2010 [11]. Therefore, discharge conferences support postdischarge management in community, through healthcare and long-term care providers [12, 13].

Preventing readmission is one of the key indicators for quality of care, because hospital readmission can be resulted from lack of standardized discharge planning [14]. Accumulating evidence has found that discharge planning or discharge summary reduce readmissions [3,15], and have cost saving effect after discharge in European countries [4, 6, 7]. In Japan, there was no significant effect of discharge services on reducing potentially avoidable readmissions among patients who received rehabilitation services in acute hospitals [16]. However, there are still not enough studies that consider the confounding effect of discharge services and show the effect of discharge services on cost of readmission. Therefore, the purpose of this study is to evaluate the impact of the discharge conference on probability of readmission and readmission costs, applying propensity scare matching method to adjust the confounding effect of discharge conference, among older people in Japan.

\section{Methods \\ Data}

We used anonymized health and long-term care insurance (LTCI) claims data from a suburban city in Japan, from April 2012 to September 2013 . This study began with 2,385 individuals from diagnosis procedure combination (DPC) hospitals, and 7,523 individuals from non-DPC hospitals. The DPC hospital provides acute inpatient care based on DPC payment system, which is designated for case-mix adjustments on reimbursements [16, 17]. We included patients who were 75 years of age or older, and admitted to an acute hospital at least once during the study period. Among the original data, the earliest admission was defined as the "index hospitalization," and the index hospitalization comprised 8,696 individuals.

In addition, we merged the health and LTCI claims data to check the utilization of LTCI facility or home services, before and after the index hospitalization. We excluded missing or incomplete values in patient sex $(n=184)$ and year of birth $(n=117)$. We also excluded individuals who died during the index 
hospitalization ( $n=299$ ), because they may have higher utilization of care prior to death, and follow-up was not possible. Finally, 8,096 individuals were included in this study. A detailed flow chart of study participants is shown in Additional File 1.

\section{Study Variables and Measures Explanatory variable}

The main explanatory variable was whether or not a person received a discharge conference. A discharge conference was defined by the health insurance fee schedule of 2012 [12]. It included discharge instructions by 1) collaboration of healthcare professionals, e.g. hospital doctor or nurse with community doctor, nurse, pharmacist, or home visiting nurses etc., which was coded as "B005" and was paid 3000 Japanese yen (JPY) in the fee schedule; 2) supporting the linkage with long-term care services, which was coded as "B005-1 (3000 JPY)"; and 3) care plan for linkage with community healthcare services or long-term care services, which was coded as "B005-2 (9000 JPY) or B005-3 (6000 JPY)" [12, 18, 19]. Because each services are alternatively provided, if a patient received one of those services, that case was defined as discharge conference.

\section{Covariates}

The covariates for this analysis included the patients' demographic information, care-needs level of LTCl, prior experience of long-term care services, and health conditions. Sex, age group divisions of 75-84 years of age and > 85 years of age, and income level were included as demographic variables. Lowincome was determined by whether the patient received additional benefits from municipals, using the health insurance premium type as a proxy variable, at the onset of the study periods.

The care-needs level of LTCI prior to the index hospitalization was used as a proxy variable of physical and mental status. The care-needs assessment has determined the eligibility of long-term care services, based on a nationally standardized needs-certification system [20]. The care-needs level was categorized to three groups: individuals who were not eligible for support; individuals who were assigned to support levels 1 or 2 or care levels 1 or 2 , which indicate mild or moderate disability of physical and mental status; and care level 3-5, which indicates severe dependence in physical and mental status. We also calculated the change in care-needs level from before and after the index hospitalization in order to adjust for the deterioration of physical and mental status.

To adjust for the experience of long-term care services prior to index hospitalization, this study defined LTCI facility service users and LTCI home service users. If patients stayed at a special nursing home for the elderly, health services facility for the elderly, sanatorium-type medical care facility, residential care facility for the elderly requiring care (excluding short-stay), group home for the elderly with dementia (excluding short-stay), or community-based welfare facility for the elderly requiring care, they were defined as users of "LTCI facility services." If patients used services of home-visit services, commuting services (such as day care services), short-stay services, and community-based services (such as night care service), they were defined as users of "LTCI home services."

We adjusted for health conditions using types of main diagnoses at the index hospitalization. First, we classified whether a patient was "DPC group" or not, as a proxy of acute inpatient cases, because a DPC group indicates prospective payment for selected diagnosis procedures, e.g. cancer surgery, and it is usually provided in large hospitals with more than 200 beds [21]. Among the patients from "non-DPC group", we used two ways for defining the health conditions. In model 1, we classified patients with one disease and two or more diseases. In model 2, we identified the specific diseases using the International Classification of Diseases, 10th revision code. The 10 most-frequent diseases (falls or fracture; pneumonia; cerebrovascular disease; essential hypertension and hypertensive renal disease; heart failure; urinary infection; problems in nervous system; nutrition related problems; diabetes mellitus; and dehydration) was included among patients with a discharge conference. The definitions of disease categories are described in the Additional File 2.

\section{Outcome variable}

In this study, the outcome variables were hospital readmission after discharge, time spent in community until readmission, length of stay (LOS) of hospital readmission, total costs and cost per day of hospital readmission. We identified the first readmission within 360 days from the index hospitalization, regardless of the cause of hospitalization.

Among the patients who experienced readmission, the time spent in community until readmission was calculated by the interval between the discharge date of the index hospitalization and the entrance date of readmission. Additionally, we calculated the LOS, total costs, and cost per day of the first readmission. The cost included reimbursement paid by the health insurance and co-paid out-of-pocket expenses by patients for the covered services. This study could not include expenditures for uncovered services. The cost per day was calculated as the total costs divided by the LOS of the readmission.

\section{Analysis Methods}

To reduce the confounding effect, we used propensity score matching to adjust the significant differences in the baseline characteristics of the patient with discharge conference and those without $[4,22]$. The propensity score was calculated based on a logistic regression of the probability of receiving a discharge conference, using sex, age group, care-needs level of LTCl, prior utilization of LTCl facility services and home services, health conditions (DPC group, one disease at non-DPC group, two or more diseases at non-DPC group), and LOS at index hospitalization among the full participants. The probability model was based on the greedy matching, without replacement option, and the nearest neighbor matching within a caliper of 0.001[22, 23]. We applied sensitivity analysis for caliper widths between 0.0001 and 0.1 , and we found that if a caliper value was smaller than 0.001 , sample size decreased rapidly while the range of propensity score was not changed. Therefore, we choose the caliper of 0.001 to get a proper balance across the two groups by discharge conference or not (See Additional File 3). This matching algorithm allows one control group (patients who did not receive a discharge conference, $\mathrm{n}=304$ ) to be matched to one treatment group (patients who received a discharge conference, $n=304$ ). We defined the full participants as "before matching" ( $n=8,096)$ and the matched sample as "after matching" $(n=608)$. 
In before and after matching groups respectively, we compared the basic characteristics and the readmission related outcomes according to patients that received a discharge conference or not, using the chi-squared test and the t-test.

To identify the relationship between discharge conference and hospital readmission, we applied two-part model. In the first part, we estimated the probability of hospital readmission using a multiple logistic regression. In the second part, among those who readmitted to hospital within 360 days, we applied multiple linear regression analysis to dependent variables of time spent in community until readmission and costs of readmission. For cost data, such as total costs and cost per day, the variables were log transformed. When the dependent variable was LOS in hospital, negative binomial regression was conducted.

For each regression analysis, we adopted two models using different covariates for proxy of health conditions. In Model 1 , we used categorical variable as DPC group, one disease at non-DPC group, two or more diseases at non-DPC group. In Model 2, we incorporated dummy variables of DPC group, and 6 specific diseases (falls or fracture, pneumonia, cerebrovascular disease, essential hypertension and hypertensive renal disease, urinary infection, and nutrition related problems) at non-DPC group, which were significantly different by those who received a discharge conference to those that did not. All analyses were conducted with SAS version 9.3 (SAS Institute Inc., Cary, NC, USA).

The datasets of this study comprised de-identified secondary data released to the researchers for research purposes, and the data analysis of this study was approved by the Ethics Committee of University of Tsukuba (Approved number: 1075) and Life Science Research Ethics and Safety, the University of Tokyo in Japan (Approved number: 15-29). In the present study, the informed consents of participants have not been conducted and given, since all the data were analyzed anonymously.

\section{Results}

\section{General characteristics of study participants}

Table 1 shows the comparison of general characteristics, divided by those who received a discharge conference to those that did not. Among the 8096 patients included in before matching, 367 (4.5\%) patients received a discharge conference. Patients who received a discharge conference showed higher proportion of women, older age group, severer care-needs level, and utilization of facility services or home services before the index hospitalization. The proportion of patients with more than two main diagnoses at the time of non-DPC hospitalization was higher among the patients with discharge conference, and they were more like to have diagnoses of falls or fracture, pneumonia, cerebrovascular disease, essential hypertension and hypertensive renal disease, urinary infection, or nutrition related problems. Average LOS was more than 2.5 times longer and total costs of index hospitalization were 1.9 times higher among patients who received a discharge conference.

In the matched sample of 608 participants, the propensity score matching seems to significantly reduce the imbalances between the two groups in the original study sample. However, there were still differences in care-needs level, prior utilization of LTCI home services, and LOS of the index hospitalization. 
Table 1

General characteristics of study participants

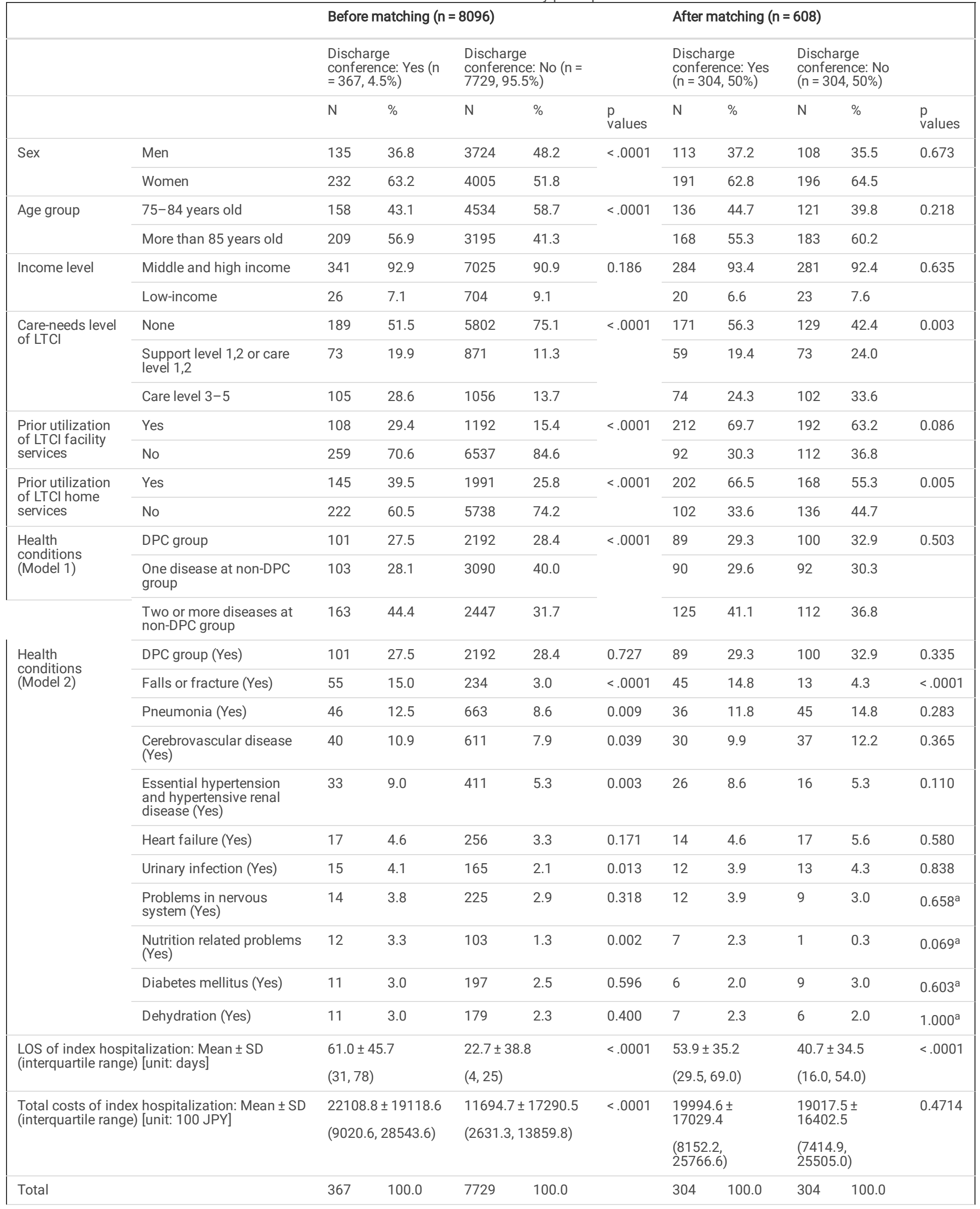


Notes. LTCI means long-term care insurance, DPC means diagnosis procedure combination, LOS means length of stay, SD means standard deviation. 100 JPY $($ Japanese yen) $=1.16$ United States Dollar (USD), based on the rate of December 31, 2012

a $p$ values from Fisher's exact test.

\section{Comparisons of readmission rates by whether a patient received a discharge conference or not}

Before matching, readmission rate was $21.9 \%$ for all study participants, and it was not different between patients who received a discharge conference (21.0\%) and those that did not (22.0\%). Within the discharge conference group, there was no difference in readmission rate by types of services, such as discharge instructions by collaboration of healthcare professionals (27.3\%), supporting the linkage with long-term care services (21.2\%), and care plan for linkage with community healthcare services $(12.5 \%)$.

When we compared the readmission rates of those care-needs level were deteriorated, discharge conference showed a significantly lower readmission rate $(16.0 \%)$ than the counterpart (33.8\%). In addition, we found that patient with discharge conference used more LTCI home services, and within the home service users, the discharge conference users showed lower readmission rate.

In the matched pairs, $21.1 \%$ readmitted among discharge conference group and $23 \%$ among the counterpart. Within the home service users, the discharge conference group showed lower readmission rate than patients without discharge conference (Table 2).

Table 2

Comparisons of readmission rates by whether a patient received a discharge conference or not

\begin{tabular}{|c|c|c|c|c|c|c|c|c|c|c|c|c|}
\hline & \multicolumn{7}{|c|}{ Before matching $(n=8096)$} & \multicolumn{5}{|c|}{ After matching $(n=608)$} \\
\hline & \multicolumn{3}{|c|}{$\begin{array}{l}\text { Discharge conference: Yes } \\
(n=367)\end{array}$} & \multicolumn{4}{|c|}{$\begin{array}{l}\text { Discharge conference: No } \\
(n=7729)\end{array}$} & \multicolumn{3}{|c|}{$\begin{array}{l}\text { Discharge conference: Yes } \\
(n=304)\end{array}$} & \multicolumn{2}{|c|}{$\begin{array}{l}\text { Discharge conferen } \\
(n=304)\end{array}$} \\
\hline & $\mathrm{N}(\%)$ & $\begin{array}{l}\text { Readmission } \\
/ \mathrm{N}\end{array}$ & $\begin{array}{l}\text { (row } \\
\%)\end{array}$ & $\mathrm{N}(\%)$ & $\begin{array}{l}\text { Readmission } \\
/ \mathrm{N}\end{array}$ & $\begin{array}{l}\text { (row } \\
\%)\end{array}$ & $\begin{array}{l}\mathrm{p} \\
\text { values }\end{array}$ & $\mathrm{N}(\%)$ & $\begin{array}{l}\text { Readmission } \\
/ \mathrm{N}\end{array}$ & $\begin{array}{l}\text { (row } \\
\%)\end{array}$ & $\mathrm{N}(\%)$ & $\begin{array}{l}\text { Readmiss } \\
\text { /N }\end{array}$ \\
\hline $\begin{array}{l}\text { Among all } \\
\text { patients }\end{array}$ & & $77 / 367$ & $(21.0)$ & & $1699 / 7729$ & $(22.0)$ & 0.651 & & $64 / 304$ & $(21.1)$ & & $70 / 304$ \\
\hline \multicolumn{13}{|c|}{ Types of services within discharge conference } \\
\hline $\begin{array}{l}\text { Collaboration } \\
\text { of healthcare } \\
\text { professionals }\end{array}$ & $\begin{array}{l}11 \\
(3.0)\end{array}$ & $3 / 11$ & $(27.3)$ & & & & $0.598^{\mathrm{a}}$ & $\begin{array}{l}10 \\
(3.3)\end{array}$ & $2 / 10$ & $(20.0)$ & & \\
\hline $\begin{array}{l}\text { Supporting } \\
\text { the linkage } \\
\text { with long- } \\
\text { term care } \\
\text { services }\end{array}$ & $\begin{array}{l}340 \\
(92.6)\end{array}$ & $72 / 340$ & $(21.2)$ & & & & & $\begin{array}{l}278 \\
(91.4)\end{array}$ & $60 / 278$ & $(21.6)$ & & \\
\hline $\begin{array}{l}\text { Care plan for } \\
\text { linkage with } \\
\text { community } \\
\text { healthcare } \\
\text { services }\end{array}$ & $\begin{array}{l}16 \\
(4.4)\end{array}$ & $2 / 16$ & $(12.5)$ & & & & & $\begin{array}{l}16 \\
(5.3)\end{array}$ & $2 / 16$ & $(12.5)$ & & \\
\hline
\end{tabular}

Change in care-needs level of LTCI before and after index hospitalization

\begin{tabular}{|c|c|c|c|c|c|c|c|c|c|c|c|c|}
\hline $\begin{array}{l}\text { Deterioration: } \\
\text { Yes }\end{array}$ & $\begin{array}{l}75 \\
(20.4)\end{array}$ & $12 / 75$ & $(16.0)$ & $\begin{array}{l}893 \\
(11.6)\end{array}$ & $302 / 893$ & (33.8) & 0.002 & $\begin{array}{l}69 \\
(22.7)\end{array}$ & $12 / 69$ & (17.4) & $\begin{array}{l}39 \\
(12.8)\end{array}$ & $13 / 39$ \\
\hline $\begin{array}{l}\text { Deterioration: } \\
\text { No }\end{array}$ & $\begin{array}{l}292 \\
(79.6)\end{array}$ & $65 / 292$ & $(22.3)$ & $\begin{array}{l}6836 \\
(88.4)\end{array}$ & $1397 / 6836$ & $(20.4)$ & 0.450 & $\begin{array}{l}235 \\
(77.3)\end{array}$ & $52 / 235$ & $(22.1)$ & $\begin{array}{l}265 \\
(87.2)\end{array}$ & $57 / 265$ \\
\hline
\end{tabular}

Utilization of LTCI facility services after index hospitalization

\begin{tabular}{lllllllllllll} 
Yes & 49 & $16 / 49$ & $(32.7)$ & $\begin{array}{l}625 \\
(8.1)\end{array}$ & $252 / 625$ & $(40.3)$ & 0.291 & 42 & $13 / 42$ & $(31.0)$ & 52 & $18 / 52$ \\
& $(13.4)$ & & & & & & $(13.8)$ & $(17.1)$ & \\
\hline No & $\begin{array}{l}318 \\
(86.7)\end{array}$ & $61 / 318$ & $(19.2)$ & $\begin{array}{l}7104 \\
(91.9)\end{array}$ & $1447 / 7104$ & $(20.4)$ & 0.607 & 262 & $51 / 262$ & $(19.5)$ & 252 & $52 / 252$ \\
& & & & & & $(86.2)$ & & & $(82.9)$ & \\
\hline
\end{tabular}

Utilization of LTCI home services after index hospitalization

\begin{tabular}{lllllllllllll} 
Yes & 97 & $16 / 97$ & $(16.5)$ & $\begin{array}{l}1165 \\
(15.1)\end{array}$ & $410 / 1165$ & $(35.2)$ & 0.000 & 87 & $15 / 87$ & $(17.2)$ & 58 & $19 / 58$ \\
& $(26.4)$ & & & & & & $(28.6)$ & $(19.1)$ & \\
\hline No & 270 & $61 / 270$ & $(22.6)$ & $\begin{array}{l}6564 \\
(84.9)\end{array}$ & $1289 / 6564$ & $(19.6)$ & 0.232 & 217 & $49 / 217$ & $(22.6)$ & 246 & $51 / 246$ \\
& $(73.6)$ & & & & & & $(71.4)$ & & & $(80.9)$
\end{tabular}

a $p$ values from Fisher's exact test. 


\section{Comparisons of time spent in community, LOS and costs of hospital readmission}

Before matching, the average periods in community until readmission was not different by discharge conference, but the LOS was longer and the cost per day was lower among the patients who received a discharge conference. After matching, there was no difference in the average value of time spent in community or LOS, but the significant difference in cost per day for the readmission still remained (Table 3).

Table 3

Comparisons of time spent in community, LOS and costs of hospital readmission by whether a patient received a discharge conference or nota

\begin{tabular}{|c|c|c|c|c|c|c|}
\hline & \multicolumn{3}{|c|}{ Before matching $(n=1776)$} & \multicolumn{3}{|c|}{ After matching $(n=134)$} \\
\hline & $\begin{array}{l}\text { Discharge } \\
\text { conference: Yes }(n= \\
77)\end{array}$ & $\begin{array}{l}\text { Discharge conference: } \\
\text { No }(n=1699)\end{array}$ & $\begin{array}{l}\mathrm{p} \\
\text { values }\end{array}$ & $\begin{array}{l}\text { Discharge } \\
\text { conference: Yes }(n= \\
64)\end{array}$ & $\begin{array}{l}\text { Discharge } \\
\text { conference: No }(n= \\
70)\end{array}$ & $\begin{array}{l}\mathrm{p} \\
\text { values }\end{array}$ \\
\hline & \multicolumn{3}{|c|}{ Mean \pm SD (interquartile range) } & \multicolumn{3}{|c|}{ Mean \pm SD (interquartile range) } \\
\hline \multirow{2}{*}{$\begin{array}{l}\text { Time spent in community until } \\
\text { readmission [unit: days] }\end{array}$} & $114.9 \pm 89.4$ & $121.5 \pm 93.5$ & \multirow[t]{2}{*}{0.544} & $122.3 \pm 93.3$ & $129.6 \pm 97.8$ & \multirow[t]{2}{*}{0.662} \\
\hline & $(46.0,175.0)$ & $(42.0,181.0)$ & & $(42.5,187.5)$ & $(49.0,198.0)$ & \\
\hline \multirow[t]{2}{*}{ LOS of readmission [unit: days] } & $35.9 \pm 33.9$ & $24.6 \pm 37.3$ & \multirow[t]{2}{*}{0.009} & $35.3 \pm 33.7$ & $32.7 \pm 40.7$ & \multirow[t]{2}{*}{0.688} \\
\hline & $(8.0,52.0)$ & $(6.0,29.0)$ & & $(8.0,53.0)$ & $(9.0,50.0)$ & \\
\hline \multirow{2}{*}{$\begin{array}{l}\text { Total costs of readmission [unit: } \\
100 \mathrm{JPY}]\end{array}$} & $14848.0 \pm 16402.2$ & $12356.0 \pm 17156.9$ & \multirow[t]{2}{*}{0.212} & $14290.6 \pm 16276.9$ & $14849.6 \pm 21932.2$ & \multirow[t]{2}{*}{0.867} \\
\hline & $(3552.2,18438.5)$ & $(2920.1,14810.7)$ & & $(3165.8,18604.1)$ & $(4234.8,17700.4)$ & \\
\hline \multirow{2}{*}{$\begin{array}{l}\text { Cost per day of readmission [unit: } \\
100 \mathrm{JPY}]\end{array}$} & $452.1 \pm 166.9$ & $591.8 \pm 395.1$ & \multirow[t]{2}{*}{$<.0001$} & $441.7 \pm 165.4$ & $514.8 \pm 253.2$ & \multirow[t]{2}{*}{0.048} \\
\hline & $(313.7,556.3)$ & $(442.3,634.9)$ & & $(311.2,555.0)$ & $(406.6,557.3)$ & \\
\hline \multicolumn{7}{|c|}{${ }^{a}$ In this analysis, only the patients who readmitted to hospital within 360 days were included. } \\
\hline \multicolumn{7}{|c|}{$\begin{array}{l}\text { Note. LOS means length of stay, SD means standard deviation. } 100 \mathrm{JPY} \text { (Japanese yen) }=1.16 \text { United States Dollar (USD), based on the rate of December } \\
31,2012 \text {. }\end{array}$} \\
\hline
\end{tabular}

\section{Effect of discharge conference on hospital readmission, time spent in community, LOS and costs of hospital readmission}

In the first part, we examined the impact of discharge conference on probability of hospital readmission using logistic regression analysis. Before matching, the odds ratio of readmission was significantly lower in patients who received a discharge conference $(O R=0.75, p=0.031)$ after controlling for demographic characteristics, care-needs level of $\mathrm{LTCl}$, deterioration of care-needs level, utilization of long-term care services, DPC group and the number of main diagnoses in Model 1 . The effect on probability of hospital readmission ( $O R=0.78, p=0.071)$ was marginally significant in Model 2 , which adjusted for the specific main diagnosis lists at non-DPC group. However, after matching, the effect of the discharge conference on readmission was not significant in both of Model 1 and Model 2.

In the second part, we estimated the effect of discharge conference on the time spent in community until readmission, hospital LOS and costs of readmission. The estimators showed that discharge conference did not have a significant impact on the time spent in community until readmission in both of before and after matching groups. Discharge conference had a significant effect on the longer LOS of hospital readmission at before matching, but after the matched pairs, there was no significant difference.

There was no significant effect of discharge conference on total costs of readmission, but a lower cost per day for readmission was identified in those with discharge conference, in both of before and after matching groups. 
Table 4

Effect of discharge conference on hospital readmission, time spent in community, LOS and costs of hospital readmission

\begin{tabular}{|c|c|c|c|c|c|c|c|c|c|c|c|c|c|c|c|}
\hline & & \multirow{2}{*}{\multicolumn{4}{|c|}{$\begin{array}{l}\text { First part: } \\
\text { Probability of readmission }\end{array}$}} & \multicolumn{10}{|c|}{ Second part: Among the patients who readmitted to hospital within 360 days ${ }^{b}$} \\
\hline & & & & & & \multicolumn{3}{|c|}{$\begin{array}{l}\text { Time spent in } \\
\text { community until } \\
\text { readmission }\end{array}$} & \multicolumn{3}{|c|}{ LOS of readmission } & \multicolumn{2}{|c|}{$\begin{array}{l}\text { Total costs of } \\
\text { readmission (Ln) }\end{array}$} & & $\begin{array}{l}\text { Co } \\
\text { rez }\end{array}$ \\
\hline & & $\begin{array}{l}\text { Odds } \\
\text { ratio }\end{array}$ & $95 \% \mathrm{Cl}$ & & $\begin{array}{l}\mathrm{p} \\
\text { values }\end{array}$ & $\beta$ & (SE) & $\begin{array}{l}\mathrm{p} \\
\text { values }\end{array}$ & $\beta$ & (SE) & $\begin{array}{l}\mathrm{p} \\
\text { values }\end{array}$ & $\beta$ & (SE) & $\begin{array}{l}\mathrm{p} \\
\text { values }\end{array}$ & $\beta$ \\
\hline \multirow[t]{2}{*}{$\begin{array}{l}\text { Before } \\
\text { matching }\end{array}$} & $\begin{array}{l}\text { Model } \\
1^{c}\end{array}$ & 0.75 & $(0.57$ & $0.97)$ & 0.031 & -5.896 & $(10.977)$ & 0.591 & 0.293 & $(0.123)$ & 0.017 & 0.185 & $(0.134)$ & 0.169 & -0 \\
\hline & $\begin{array}{l}\text { Model } \\
2^{d}\end{array}$ & 0.78 & $(0.60$ & $1.02)$ & 0.071 & -4.169 & (10.993) & 0.705 & 0.298 & $(0.123)$ & 0.015 & 0.173 & $(0.134)$ & 0.196 & $-0:$ \\
\hline \multirow[t]{2}{*}{$\begin{array}{l}\text { After } \\
\text { matching }\end{array}$} & $\begin{array}{l}\text { Model } \\
1^{\mathrm{C}}\end{array}$ & 0.90 & $(0.60$ & 1.34) & 0.604 & 4.770 & $(16.854)$ & 0.778 & 0.141 & $(0.178)$ & 0.428 & 0.033 & $(0.203)$ & 0.871 & -0 \\
\hline & $\begin{array}{l}\text { Model } \\
2^{\mathrm{d}}\end{array}$ & 0.97 & $(0.64$ & $1.45)$ & 0.869 & 7.001 & $(17.275)$ & 0.686 & 0.165 & $(0.176)$ & 0.347 & 0.020 & $(0.207)$ & 0.925 & -0 \\
\hline
\end{tabular}

${ }^{a}$ In the first part, the number of participants was 8096 at the group of before matching, and 608 at the group of after matching.

${ }^{b}$ In the second part, only the patients who readmitted to hospital within 360 days were included. The number of participants was 1776 at the group of before the group of after matching.

${ }^{c}$ The Model 1 adjusted sex, age group, income level, care-needs level of LTCl, change in care-needs level of LTCl, prior utilization of LTCI facility and home ser conditions (DPC group, one disease at non-DPC group, two or more diseases at non-DPC group) during the index hospitalization.

d The Model 2 adjusted sex, age group, income level, care-needs level of LTCl, change in care-needs level of LTCl, prior utilization of LTCI facility and home sel conditions (DPC group, falls or fracture, pneumonia, cerebrovascular disease, essential hypertension and hypertensive renal disease, urinary infection, and nu at non-DPC group) during the index hospitalization.

Notes. LOS means length of stay.

\section{Discussion}

Using health and long-term care insurance claims data, this study showed that $4.5 \%$ of older inpatients in a suburban city received a discharge conference in Japan. We compared the hospital readmission, time spent in community until readmission, and subsequent LOS and costs of readmission, according to whether or not a patient received a discharge conference. Using propensity score matching, we tried to adjust for the baseline difference of patient's characteristics, and to examine the pure effect of discharge conference. The results confirmed that once the confounding has been controlled, discharge conference has impact on reducing the cost per day for readmission.

Not surprisingly, the patients with discharge conference had worse functional and health status than non-discharge conference group. The patient with discharge conference had a higher proportion of women, 85 years of age and older, prior experience of long-term care services and severer care-needs level, higher proportion of two or more main diagnoses, longer LOS and higher total costs at index hospitalization. The direction of bias by patient characteristics is not clear. Those who were expected to be readmitted were more likely to use discharge conference due to higher needs for medical management and supportive care. On the other hand, discharge conference group were expected to less likely to be readmitted, due to high proportion of women or those with longer LOS. Many older women are living alone, may be less likely to use hospital services under insufficient support from other family members. In addition, longer LOS at the index hospitalization may reduce the probability of readmission within the limited follow-up periods. These suggests the high needs for adjustment of baseline characteristics of patients, because the potential confounders can make biased estimates of the policy effect [23].

The effect of discharge conference on the probability of readmission was not consistent between before and after matching sample. Only at before marching, it showed a reduced odds ratio of readmission, which is accordance with previous studies $[3,15]$, but the estimates of after matching group concluded no significant effect. It is well established that discharge planning or a discharge summary has an impact of reducing the rate of hospital readmission for older patients with medical conditions in western countries [2, 5, 6, 24-27], but did not reduce 30-day potentially avoidable readmissions after rehabilitation services in Japan [16]. These gaps might be caused by differences in specific interventions and target population in each studies; such as patients with heart failure [2, 24], pulmonary disease [5], or acute stroke with functional limitations [28]. In addition, Japan has a generous coverage of health insurance and longer LOS in acute care than other countries [29], as both acute and post-acute care are provided during the same inpatient episode generally [16], therefore, the different health systems may induce the gaps in discharge conference effect.

Although we could not find a statistically significant difference on time spent in community until readmission, there were former findings that explained the extended times in community before emergency readmission [6] or first hospital readmission [27] among older patients who received comprehensive discharge planning supports. In addition, discharge conference did not have significant effect on LOS in this study. Previous studies also showed that receiving multidisciplinary discharge planning or telephone follow-up did not significantly reduce the number of days in the hospital upon readmission [24], or hospital nights during 12 months after discharge [7]. 
Discharge conference reduced a cost per day of readmission, although it did not have significant effect on total costs for readmission. It might decrease the intensity of care rather than the volume of services for readmission. Discharge conference might increase communication between service providers, while reduce treatment delays or worsening of illness, and it may reduce the need for high-cost care at acute hospital during the readmission. However, we need to careful interpret as the definition of cost is varied by studies, for example, hospitalization cost were estimated using the number of readmission days and emergency department visit [6, 7], some studies included post-acute care (e.g. home health, skilled nursing facility, hospice) [4], or estimated cost of outpatient visits after discharge [30]. Previous literature found inconclusive results about costs $[3,15]$, while recent studies reported that there were cost savings in the Care Transitions Intervention or discharge planning at several practical settings $[4,6,7,26,30]$.

Although the sample size was small, sub-analysis showed that the better continuity of care may work in reducing the readmission for those whom experienced worsening of conditions or needed home services. For example, there were higher portion of patients who experienced a deterioration of care-needs level among the discharge conference group, and they were less re-hospitalized. Moreover, among the LTCI home service users, the discharge conference group experienced lower hospital readmission.

The results of our study suggest that a discharge conference can be a buffer to hospitalization. During a discharge conference, long-term care service providers interact with hospital doctors and nurses to make a plan for community-based home care. For example, home visiting nurses learn how to provide the same treatments as those provided in hospital during the discharge conference. They share information about the patient's clinical needs and practical skills, as well as visiting schedules and caregiver's socio-economic situation under an agreement of the patient and/or family members. The findings of this study call for closer coordination between medical providers and long-term care providers for the management of older patients at discharge [31].

When we interpret the results, we need to consider the diverse function of discharge services and healthcare delivery systems in each country. In North America and European countries, discharge planning has been implemented with a team approach, such as the Integrated Care Pathway [28, 32], but the main professionals were different, involving nurses [24, 26, 33], doctors [6], pharmacists [34, 35], and social workers [36]. Discharge plan and/or summary emphasizes the connection with outpatient doctors $[2,6]$, and the discharge coordinator assess patient needs, attend daily rounds, submit progress reports to the primary care provider, and support the patient's participation [25, 37,38]. On the other hands, in Japan, a discharge conference has the role of connecting acute hospitals and long-term care services smoothly. Therefore, the effect of discharge conference on readmission and related health care expenditure can be different by countries according to its public financing and coverage system of health and long-term care, and detailed options of policy interventions need to take into account the context of each country.

At the same time, this study showed that service variations within a discharge conference need to be strengthened because majority of services were provided by one service type. For example, more than $90 \%$ received services that supporting the linkage with long-term care services as we showed in Table 2 . Since 2016, the role of collaboration of healthcare professionals has been enhanced in the fee schedule [39], therefore, diversification of services needs to be taken attention.

This study suggests that a discharge conference can be a useful to reduce the cost per day of hospital readmission among older patients. Our estimated cost saving per day for readmission was about $20 \%$, in both of before matching and after matching sample. Although the discharge conference users were less than $5 \%$ amongst older inpatients, if the $20 \%$ decrease is widely acceptable among country, the implementation of discharge conferences can be cost saving. At the same time, as discharge conference could not effect on reducing the amount of LOS, it could not cut down the total costs. If the discharge conference works well for both of reducing the cost per day and LOS of readmission, it may have merit in practice that lower health insurance spending while mitigating highly intensive care among older population.

There were low utilization rates of discharge conference in the suburban city of Japan, compared with the Medicare or Medicaid systems where discharge planning is mandatory [3]. There are no general guidelines for discharge conferences in Japan, and many trainees felt there was a lack of available training curriculums and feedback interventions regarding the discharge process [40]. On the other hands, clinical guidance has been issued by professional bodies in the United Kingdom, the United States, Australia, and Canada [3]. Therefore, policy makers may need profound evidences of the discharge conference using nationally representative sample with more diverse scenario models. In addition, it is recommended that clear standards, relevant training, and routine audit to improve the discharge communication [41]. If proper education and guidelines are provided, the implementation of discharge conferences by diverse healthcare providers can be encouraged in Japan.

\section{Limitations}

This study has several limitations. First, we could not consider the specific diagnoses in DPC group due to lack of available information, therefore we identified simply whether a patient is in DPC group or not. Further work needs to take into account the detailed information of DPC group. Second, this study could not account for the hospital characteristics, even though there is possibility of variations in the quality of discharge services by hospitals [40]. Because the study population was limited to one suburban area, the number of patients per hospital was too small to compare the hospital characteristics. Therefore, future studies need to use nationally representative data, including hospital characteristics.

\section{Conclusions}

This study examined the effect of a discharge conference on readmission among older patients in a suburban city in Japan. Despite there has been a low implementation rate of discharge conferences, those who received a discharge conference showed lower cost per day of readmission after adjusting for effect of confounding. Discharge conferences might have preventive role of becoming severer case, by integrative role between acute and community-based care. This study suggests that there are potential strategies to improve transitional services using a discharge conference throughout the acute and long-term care sector amongst older patients. 


\section{Abbreviations}

DPC

Diagnosis procedure combination

LTCI

Long-term care insurance

JPY

Japanese yen

LOS

Length of stay

\section{Declarations}

\section{Ethics approval and consent to participate}

The datasets of this study comprised de-identified secondary data released to the researchers for research purposes, therefore, the consent to participants was not necessary. The data analysis of this study was approved by the Ethics Committee of University of Tsukuba (Approved number: 1075) and Life Science Research Ethics and Safety, the University of Tokyo (Approved number: 15-29) in Japan.

\section{Consent for publication}

N/A

\section{Availability of data and materials}

The health and long-term care insurance claims data analyzed during the current study were set up in the designated computers with no internet connections in University of Tsukuba. The usage of the datasets was available only for the approved researchers by the Ethics Committee of University of Tsukuba (Approved number: 1075) or Life Science Research Ethics and Safety, the University of Tokyo (Approved number: 15-29).

\section{Competing interests}

The authors declare that they have no competing interests.

\section{Funding}

This study was funded by the Ministry of Health, Labour and Welfare (H27-seisaku-senyaku-012, PI: Nanako Tamiya).

\section{Authors' contributions}

NT, BJ contributed in the design of the study, and BJ, NT, XJ contributed to literature review, analysis of the data, and writing of the first draft. KI, SY, TI collected the data and provided technical advice. BJ TN, XJ, SY, KT, TI contributed to writing and revising of the manuscript. NT managed the entire study process. All authors read and approved the final manuscript.

\section{Acknowledgements}

Preliminary findings of this research were presented at the poster session of 4th International Conference on Global Aging Tsukuba, on September $19,2016$.

\section{References}

1. Coleman EA, Berenson RA. Lost in transition: challenges and opportunities for improving the quality of transitional care. Ann Intern Med. 2004;141(7):5336. Epub 2004/10/07. PubMed PMID: 15466770.

2. Al-Damluji MS, Dzara K, Hodshon B, Punnanithinont N, Krumholz HM, Chaudhry SI, et al. Association of discharge summary quality with readmission risk for patients hospitalized with heart failure exacerbation. Circulation Cardiovascular quality and outcomes. 2015;8(1):109-11. Epub 2015/01/15. doi: 10.1161/circoutcomes.114.001476. PubMed PMID: 25587092; PubMed Central PMCID: PMCPmc4303529. 
3. Goncalves-Bradley DC, Lannin NA, Clemson LM, Cameron ID, Shepperd S. Discharge planning from hospital. Cochrane Database Syst Rev. 2016; (1):Cd000313. Epub 2016/01/28. doi: 10.1002/14651858.CD000313.pub5. PubMed PMID: 26816297.

4. Gardner R, Li Q, Baier RR, Butterfield K, Coleman EA, Gravenstein S. Is implementation of the care transitions intervention associated with cost avoidance after hospital discharge? Journal of general internal medicine. 2014;29(6):878-84.

5. Lainscak M, Kadivec S, Kosnik M, Benedik B, Bratkovic M, Jakhel T, et al. Discharge coordinator intervention prevents hospitalizations in patients with COPD: a randomized controlled trial. Journal of the American Medical Directors Association. 2013;14(6):450. e1-. e6.

6. Legrain S, Tubach F, Bonnet-Zamponi D, Lemaire A, Aquino JP, Paillaud E, et al. A New Multimodal Geriatric Discharge-Planning Intervention to Prevent Emergency Visits and Rehospitalizations of Older Adults: The Optimization of Medication in AGEd Multicenter Randomized Controlled Trial. Journal of the American Geriatrics Society. 2011;59(11):2017-28.

7. Torisson G, Minthon L, Stavenow L, Londos E. Multidisciplinary intervention reducing readmissions in medical inpatients: a prospective, non-randomized study. Clinical interventions in aging. 2013;8.

8. Tamiya N, Noguchi H, Nishi A, Reich MR, lkegami N, Hashimoto H, et al. Population ageing and wellbeing: lessons from Japan's long-term care insurance policy. The Lancet. 2011;378(9797):1183-92. doi: 10.1016/S0140-6736(11)61176-8.

9. Nagata S, Tabata M, Ooshima H, Murashima S, Sumi N, Haruna M. Current status of discharge planning activities and systems: National survey of discharge planning in Japan. Japan Journal of Nursing Science. 2004;1(2):87-97.

10. MHLW. Major revised items in revision of medical fee schedule in 2008: Ministry of Health, Labour and Welfare, Japan; 2008 [17 January 2016 ]. Available from: http://www.mhlw.go.jp/shingi/2008/02/dl/s0213-4a.pdf.

11. MHLW. Discharge arrangement (medical and long-term care collaboration). Ministry of Health, Labour and Welfare, Japan; 2011 (in Japanese).

12. MHLW. Revision of medical fee in 2012: Ministry of Health, Labour and Welfare, Japan; 2012 [17 January 2016]. Available from: http://www.mhlw.go.jp/stf/seisakunitsuite/bunya/kenkou_iryou/iryouhoken/iryouhoken15/.

13. Nagata S, Tomura H, Murashima S. Expansion of discharge planning system in Japan: Comparison of results of a nationwide survey between 2001 and 2010. BMC health services research. 2012;12(1):237.

14. Wong EL, Yam CH, Cheung AW, Leung MC, Chan FW, Wong FY, et al. Barriers to effective discharge planning: a qualitative study investigating the perspectives of frontline healthcare professionals. BMC health services research. 2011;11(1):242. doi: 10.1186/1472-6963-11-242.

15. Shepperd S, McClaran J, Phillips CO, Lannin NA, Clemson LM, McCluskey A, et al. Discharge planning from hospital to home. Cochrane Database Syst Rev. 2010;(1):CD000313. doi: doi: 10.1002/14651858.CD000313.pub3.

16. Mitsutake S, Ishizaki T, Tsuchiya-Ito R, Uda K, Teramoto C, Shimizu S, et al. Associations of hospital discharge services with potentially avoidable readmissions within 30 days among older adults after rehabilitation in acute care hospitals in Tokyo, Japan. Archives of physical medicine and rehabilitation. 2020

17. MHLW. Procedures of medical institutions pertaining to DPC system: Ministry of Health, Labour and Welfare; 2012 [17 January 2016 ]. Available from: http://www.mhlw.go.jp/stf/shingi/2r98520000025zci-att/2r98520000026eyh.pdf.

18. MHLW. Standard specification of claims fee schedule for on-line or optical disc (Medical part): Ministry of Health, Labour and Welfare, Japan; 2012 [17 January 2016]. Available from: http://www.iryohoken.go.jp/shinryohoshu/file/spec/24bt2_1_hyoujun.pdf.

19. MHLW. Standard specification of claims fee schedule for on-line or optical disc (DPC part): Ministry of Health, Labour and Welfare, Japan; 2012 [17 January 2016]. Available from: http://www.iryohoken.go.jp/shinryohoshu/file/spec/24bt2_2_hyoujun_dpc.pdf.

20. Tsutsui T, Muramatsu N. Care-Needs Certification in the Long-Term Care Insurance System of Japan. Journal of the American Geriatrics Society. 2005;53(3):522-7.

21. Ishii M. DRG/PPS and DPC/PDPS as Prospective Payment Systems. Japan Medical Association journal: JMAJ. 2012;55(4):279-91.

22. Austin PC. An Introduction to Propensity Score Methods for Reducing the Effects of Confounding in Observational Studies. Multivariate Behavioral Research. 2011;46(3):399-424. doi: 10.1080/00273171.2011.568786.

23. Oakes JM, Johnson PJ. Propensity score matching for social epidemiology. Methods in social epidemiology. 2006;1:370-93.

24. Laramee AS, Levinsky SK, Sargent J, Ross R, Callas P. Case management in a heterogeneous congestive heart failure population: a randomized controlled trial. Archives of Internal Medicine. 2003;163(7):809-17.

25. Voss R, Gardner R, Baier R, Butterfield K, Lehrman S, Gravenstein S. The care transitions intervention: translating from efficacy to effectiveness. Arch Intern Med. 2011;171(14):1232-7. Epub 2011/07/27. doi: 10.1001/archinternmed.2011.278. PubMed PMID: 21788540.

26. Coleman EA, Parry C, Chalmers S, Min SJ. The care transitions intervention: results of a randomized controlled trial. Arch Intern Med. 2006;166(17):18228. Epub 2006/09/27. doi: 10.1001/archinte.166.17.1822. PubMed PMID: 17000937.

27. Bowles KH, Hanlon A, Holland D, Potashnik SL, Topaz M. Impact of discharge planning decision support on time to readmission among older adult medical patients. Professional case management. 2014;19(1):29.

28. Sulch D, Perez I, Melbourn A, Kalra L. Randomized controlled trial of integrated (managed) care pathway for stroke rehabilitation. Stroke. 2000;31(8):192934.

29. OECD. OECD Health Statistics: Health care utilisation; 2018 [04 May 2020]. Available from: https://data.oecd.org/healthcare/length-of-hospital-stay.htm.

30. Jack BW, Chetty VK, Anthony D, Greenwald JL, Sanchez GM, Johnson AE, et al. A reengineered hospital discharge program to decrease rehospitalization: a randomized trial. Ann Intern Med. 2009;150(3):178-87. Epub 2009/02/05. PubMed PMID: 19189907; PubMed Central PMCID: PMCPmc2738592. 
31. Murtaugh CM, Deb P, Zhu C, Peng TR, Barron Y, Shah S, et al. Reducing Readmissions among Heart Failure Patients Discharged to Home Health Care: Effectiveness of Early and Intensive Nursing Services and Early Physician Follow-Up. Health services research. 2016; [Epub ahead of print]. Epub 2016/07/30. doi: 10.1111/1475-6773.12537. PubMed PMID: 27468707.

32. Campbell H, Hotchkiss R, Bradshaw N, Porteous M. Integrated care pathways. BMJ. 1998;316(7125):133-7. doi: 10.1136/bmj.316.7125.133.

33. Goldman LE, Sarkar U, Kessell E, Guzman D, Schneidermann M, Pierluissi E, et al. Support from hospital to home for elders: a randomized trial. Annals of internal medicine. 2014;161(7):472-81.

34. Farris KB, Carter BL, Xu Y, Dawson JD, Shelsky C, Weetman DB, et al. Effect of a care transition intervention by pharmacists: an RCT. BMC health services research. 2014;14(1):1.

35. Reidt SL, Holtan HS, Larson TA, Thompson B, Kerzner LJ, Salvatore TM, et al. Interprofessional Collaboration to Improve Discharge from Skilled Nursing Facility to Home: Preliminary Data on Postdischarge Hospitalizations and Emergency Department Visits. Journal of the American Geriatrics Society. 2016;64(9):1895-9. Epub 2016/07/08. doi: 10.1111/jgs.14258. PubMed PMID: 27385197.

36. Altfeld SJ, Shier GE, Rooney M, Johnson TJ, Golden RL, Karavolos K, et al. Effects of an enhanced discharge planning intervention for hospitalized older adults: a randomized trial. The Gerontologist. 2013;53(3):430-40.

37. Naylor MD, Brooten D, Campbell R, Jacobsen BS, Mezey MD, Pauly MV, et al. Comprehensive discharge planning and home follow-up of hospitalized elders: a randomized clinical trial. Jama. 1999;281(7):613-20.

38. Balaban RB, Weissman JS, Samuel PA, Woolhandler S. Redefining and redesigning hospital discharge to enhance patient care: a randomized controlled study. Journal of general internal medicine. 2008;23(8):1228-33.

39. MHLW. Revision of medical fee in 2016: Ministry of Health, Labour and Welfare, Japan; 2016 [17 January 2016]. Available from:

http://www.mhlw.go.jp/stf/seisakunitsuite/bunya/0000112857.html.

40. Al-Damluji MS, Dzara K, Hodshon B, Punnanithinont N, Krumholz HM, Chaudhry SI, et al. Hospital variation in quality of discharge summaries for patients hospitalized with heart failure exacerbation. Circulation Cardiovascular quality and outcomes. 2015;8(1):77-86. Epub 2015/01/15. doi:

10.1161/circoutcomes.114.001227. PubMed PMID: 25587091; PubMed Central PMCID: PMCPmc4303507.

41. Cresswell A, Hart M, Suchanek O, Young T, Leaver L, Hibbs S. Mind the gap: Improving discharge communication between secondary and primary care. BMJ quality improvement reports. 2015;4(1). Epub 2016/01/07. doi: 10.1136/bmjquality.u207936.w3197. PubMed PMID: 26734391; PubMed Central PMCID: PMCPmc4693041.

\section{Supplementary Information}

Additional File 1. Flow chart of study participants

Additional File 2. The lists and definitions of disease categories for index hospitalization among the patients from non-DPC group

Additional File 3. Sensitivity analysis by caliper widths: The number of participants and propensity score

\section{Supplementary Files}

This is a list of supplementary files associated with this preprint. Click to download.

- supplement4.docx

- supplement5.docx

- supplement6.pdf 